\title{
Digital Images Analysis on a Mobile Device to Estimate Surface Area and Volume of Mango Fruit (Mangifera indica L.)
}

\author{
Loera-Alvarado, Gerardo ${ }^{1}$; Chávez-Franco, Sergio H. ${ }^{2 *}$; Carrillo-Salazar, José A. ${ }^{2}$, \\ González-Camacho, Juan M. ${ }^{2}$; Suarez-Espinosa, Javier²; Valle-Guadarrama, Salvador ${ }^{3}$
}

${ }^{1}$ Colegio de Postgraduados Campus San Luis Potosí, Iturbide No. 73, Salinas de Hidalgo, San Luis Potosí, CP. 78600, México. ${ }^{2}$ Colegio de Postgraduados Campus Montecillo, Carretera MéxicoTexcoco km 36.5, Montecillo, Texcoco, Estado de México, CP. 56230, México. ${ }^{3}$ Departamento de Ingeniería Agroindustrial, Universidad Autónoma Chapingo, Carretera México-Texcoco, km 38.5, Chapingo, Estado de México, CP. 56230, México.

*Corresponding author: sergiocf@ecolpos.mx

\section{ABSTRACT}

Objective: To develop a technique based on the partition method, to estimate the surface area and volume of mango fruit (Mangifera indica L. cv. "Ataulfo") using two digital orthogonal images, obtained and processed on a mobile device with the Android ${ }^{\circledR}$ operating system, segmented by different discriminants.

Design/Methodology/Approach: A technique was developed to estimate the surface area and volume of "Ataulfo" mango fruit based on digital images and was implemented directly on a smartphone with the Android ${ }^{\circledR}$ operating system. Three discriminants were evaluated for segmentation (red channel, green channel, and HIS color intensity) and applied in $n=30$ fruit. The precision and accuracy of the technique was determined.

Results: The surface area and volume of the fruit when estimated using the red channel presented a coefficient of variation of less than $2.0 \%$ in both variables and the estimation error was less than $3 \%$ for surface area and less than $5 \%$ for volume.

Study Limitations/Implications: This technique was limited to fruit with an elliptical cross-section and smooth surface. Findings/Conclusions: The proposed technique is a non-destructive alternative to estimate the surface area and volume of "Ataulfo" mango fruit with a reasonable margin of error and can be implemented directly on an Android ${ }^{\circledR}$ device using only the red channel as a segmentation discriminant.

Key words: Android ${ }^{\circledR}$, elliptical frustum, segmentation, smartphone.

\section{INTRODUCTION}

Man (Mangifera indica L.) is a tropical crop of global importance. Mexico is the number one exporter MahgO and produces more than 50 cultivars. One of these is "Ataulfo", whose organoleptic and nutritional characteristics make it acceptable for the international market (Palafox-Carlos et al., 2012; Sáyago-Ayerdi et al., 2013). 
The size of horticultural products, in addition to being a variable for quality, affects physical properties such as surface area and volume. These properties are necessary for the study of physiological processes such as phenomena related to gas permeability, transpiration, and cooling (Goñi et al., 2007; Valle-Guadarrama et al., 2009)

The analysis of digital images has made possible the development of non-destructive methods for estimating surface area and volume of horticultural products. The best results were found with the use of a 3D scanner (Uyar and Erdogdu, 2009; Kelkar et al., 2011), infrared sensors (Wang and Li, 2014), and commercial software for computer-aided design (Goñi et al., 2007).

One alternative is the use of systems that only require a digital camera and a processing unit (Saltani et al., 2011). However, these systems have been applied in products with a regular shape such as: citrus, watermelon, melon or egg (Koc, 2007; Fellegari and Navid, 2011). In mango fruit, weight has been correlated to the sizes measured directly in digital images (Teoh and Syaifudin, 2007; Spreer and Müller, 2011). The availability

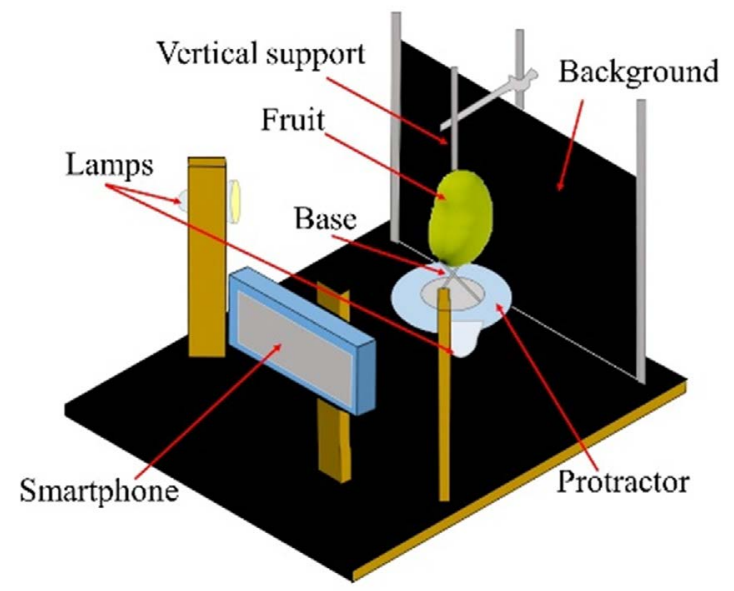

Figure 1. Image capturing system to estimate surface and volume of mango fruit.
(Mangifera indica L. cv "Ataulfo") fruit were used, acquired in the local market of Texcoco, Estado de México.

\section{Capture conditions}

Each fruit was placed on a revolving base, and two fluorescent lamps (28 W, $6500 \mathrm{~K}, \mathrm{D} 65$ and $1747 \mathrm{~lm}$, Promilight ${ }^{\circledR}$, made in China) were placed $21.5 \mathrm{~cm}$ from the center of the fruit, angled at $45^{\circ}$ against a black background. A smartphone (CellAllure Book2 model CAPHG28-01, Android $^{\circledR}$ 4.4.2) was placed at 20.0 $\mathrm{cm}$ from the fruit to take a photo of the widest side of the fruit and another after turning it manually $90^{\circ}$ (Figure 1).

\section{Image capture method}

The images were captured using the device's default photo application with the automatic settings, with a resolution of $640 \times 480$ pixels in the JPEG format at 24 bits. Each fruit was processed five times. In total, $n=300$ images were captured.

Preprocessing and grayscale image generation

A median filter with a $5 \times 5$ matrix was applied to the RGB images. Of the filtered images, three 8-bit images were generated in grayscale, based of smartphones with cameras and a high processing capacity represents an alternative for estimating diverse variables such as: the color index and yield of citruses (Cubero et al., 2018) or the chlorophyll content (Vesali et al., 2017). Thus, it is possible to combine the analysis of digital images with the advantages of mobile devices to estimate the surface area and volume of "Ataulfo" mango fruit. For these reasons, the objective of this study was to develop a technique based on the partition method in order to estimate the surface area and volume of "Ataulfo" mango fruit using two orthogonal digital images obtained and processed on a mobile device with Android ${ }^{\circledR}$ operating system, segmented by different discriminants.

\section{MATERIALS AND METHODOLOGY}

\section{Plant material}

This study was conducted in the Postharvest Physiology laboratory of Colegio de Postgraduados. Ripe mango on: the red channel value $(R C)$, the green channel value $(G C)$, and the color intensity $(\boldsymbol{I})$ of the HSI space (hue, saturation, and intensity) (Figure 2). The blue channel did not provide sufficient information for segmentation.

\section{Segmentation of images in grayscale}

The images were binarized using a local minimum (Gonzalez and Woods, 2007). Within the histogram, the local maximums were identified in the low intensity zone and in the high intensity zone. The threshold was determined as the local minimum between by the local maximums (Figure 3).

\section{Analysis of digital images in grayscale}

The grayscale images were processed and analyzed directly in the application for mobile devices, which was developed on Google's open source Android Studio 3.2.2 platform (Figure 4). 

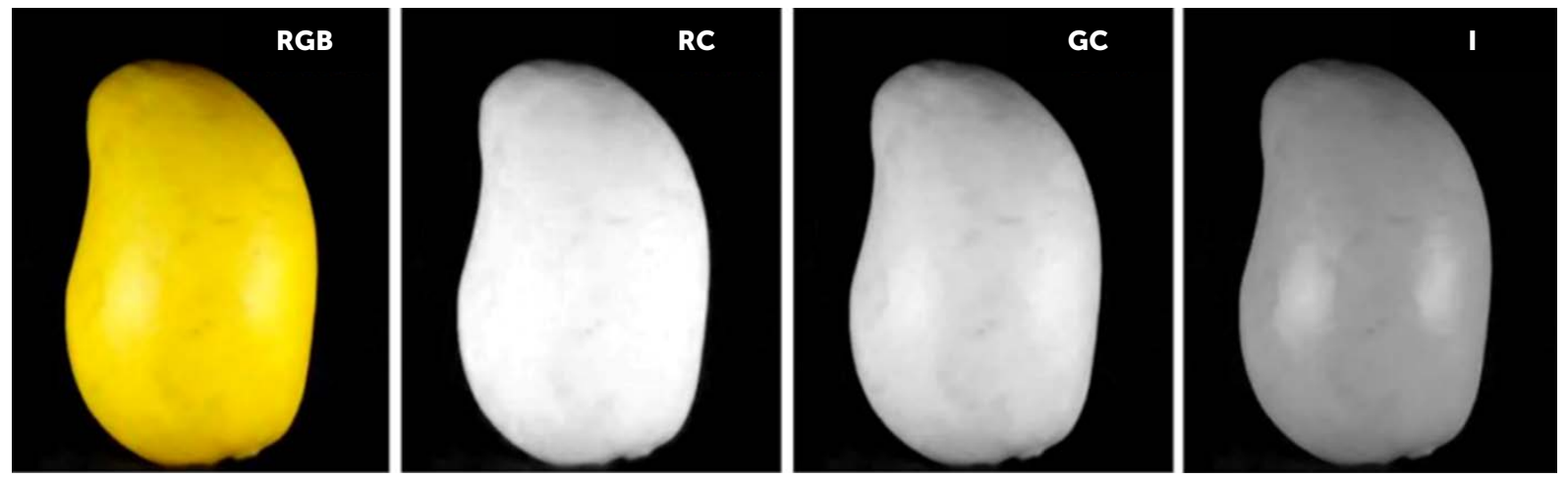

Figure 2. RGB image and grey scale images; red channel (RC), green channel (GC) and HSI color intensity (I).

\section{Estimation of surface area and volume}

The fruit was viewed as a group of elliptical frustums vertically overlapped and the lateral surface area and volume of each cone was estimated. According to

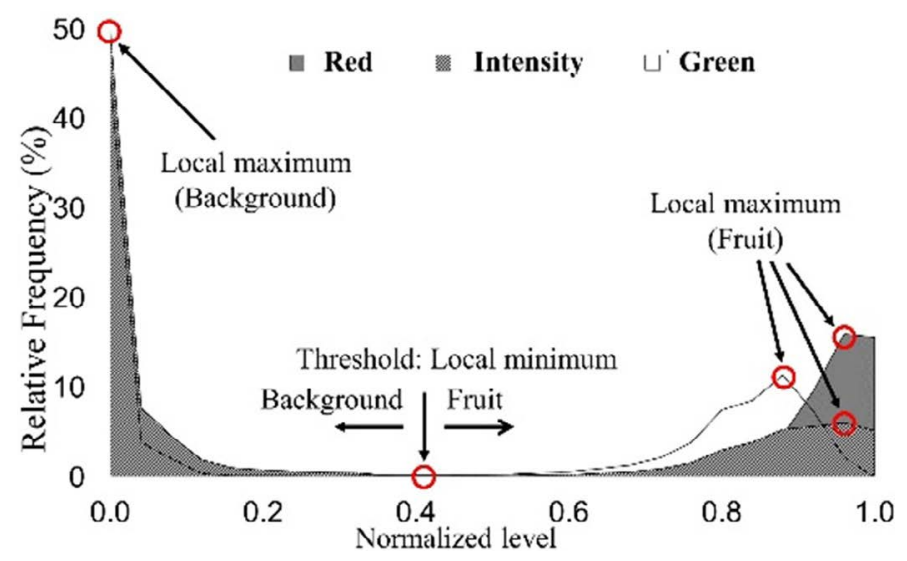

Baldor et al. (1997), an elliptical frustum is characterized by the semi-major axis $(r)$ and the semi-minor axis ( $s$ ) in each of its bases, and its height ( $h$ ). The values of $r$ were obtained from the image taken at $0^{\circ}$, the $s$ values were obtained from the image taken at $90^{\circ}$ according to the number of pixels that corresponded to the fruit in each row, while $h$ was kept constant at one pixel (Figure 5).

The surface area could be estimated using the sum of the lateral surface area of each cone, obtained as the mean perimeter of the bases multiplied by the generatrix (Equations 1 and 2) (Khojastehnazhand et al., 2009).

$$
A_{f}=\frac{\pi}{2} \sum_{i=1}^{n-1}\left(r_{i}+s_{i}+r_{i+1}+s_{i+1}\right) \star G_{i}
$$

Figure 3. Histogram of the normalized values of the red channel, green

$$
G_{i}=\left(n^{2}+\left(\frac{r_{i}+s_{i}}{2}-\frac{r_{i+1}+s_{i+1}}{2}\right)^{2}\right)^{1 / 2}
$$
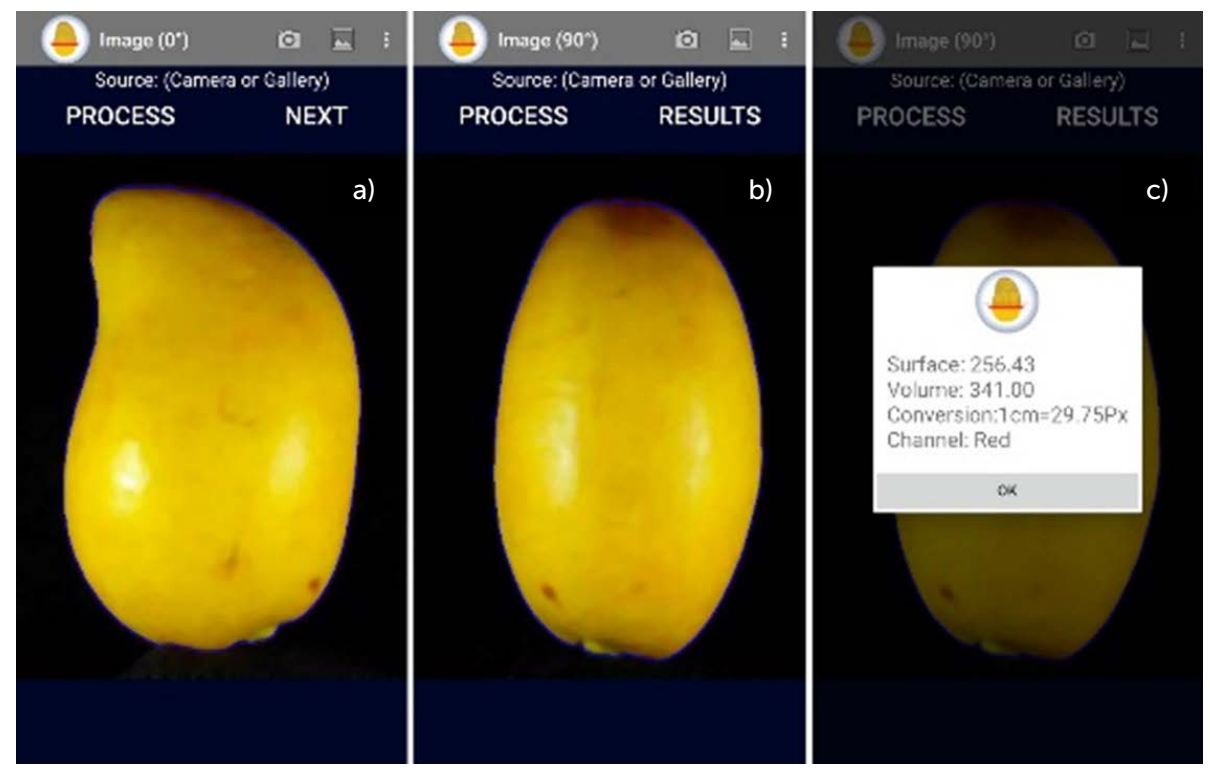

Figure 4. Android ${ }^{\circledR}$ application to estimate surface and volumen of mango fruit. a) and b) Contour identification on both fruit images $\left(0^{\circ}\right.$ and $\left.90^{\circ}\right)$ and c) Results.
Where $i$ indicates the row of pixels at the base of the cone; $n$ is the total pixel rows of the fruit; $h$ is the cone height (1Px); $G_{i}$ is the generatrix; and $A_{f}$ is the surface area of the fruit $\left(P x^{2}\right)$. Following Khojastehnazhand et al. (2009), the fruit volume was estimated as the sum of the volume of each cone, calculated as the average of the surface area of the bases multiplied by the cone height (Equation 3).

$$
V_{f}=\frac{\pi}{2} \sum_{i=1}^{n-1}\left[\left(r_{i} * s_{i}\right)+\left(r_{i+1} * s_{i+1}\right)\right] * h
$$



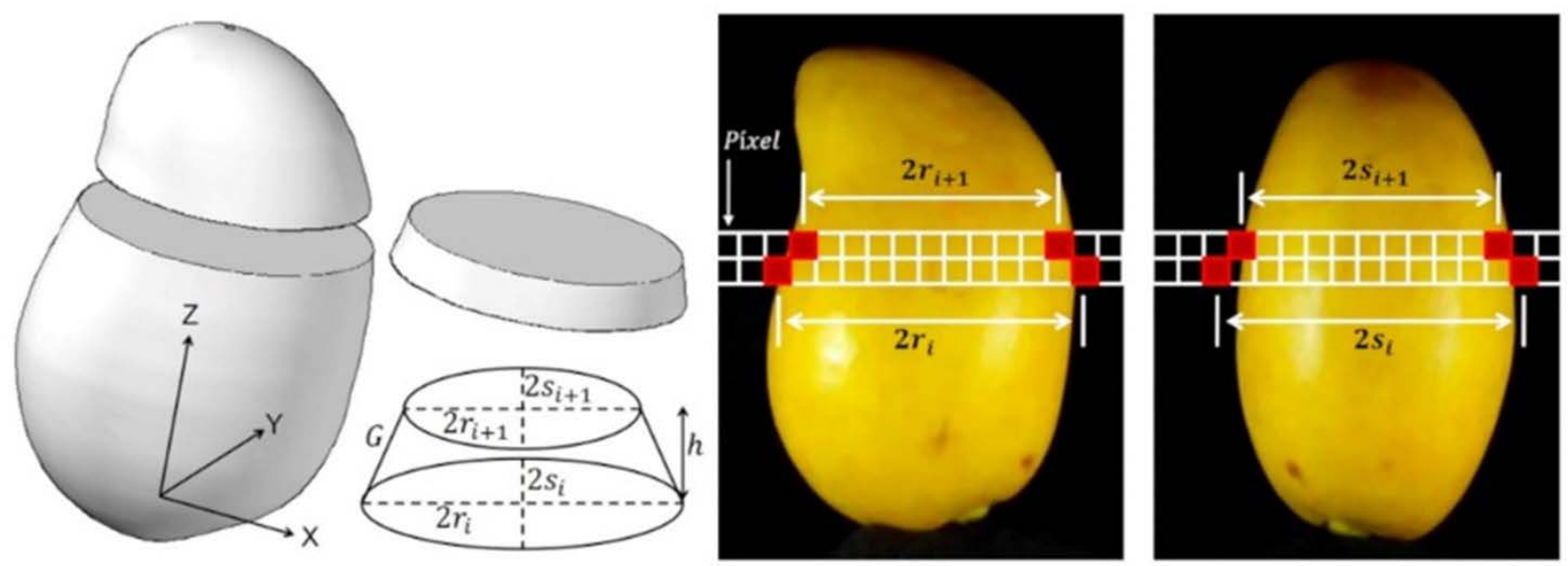

Figure 5. Mango fruit divided by elliptical frustums and variables of the frustum obtined from digital images.

Where $i$ is the row of pixels where the cone's base was measured; $n$ is the total pixel rows of the fruit; $h$ is the height $(1 P x)$; and $V_{f}$ is the fruit volume, in $P x^{3}$.

\section{Image calibration}

A measuring stick was photographed in a vertical position, placed at the same distance as the fruit, and the spacing between the graduated marks was measured in the resulting image with the Image Tool 3.0 software (University of Texas Health Science Center at San Antonio). One pixel represented on average $0.0336 \mathrm{~cm}$, and this value was used as a conversion factor to $\mathrm{cm}^{2}$ and $\mathrm{cm}^{3}$ for surface area and volume, respectively.

\section{Measurement of reference surface area and volume of fruit}

The fruit volume was measured using the water displacement method in a container $(1200 \pm 1.75 \mathrm{~mL})$. The fruit was placed inside the container, then $1000 \mathrm{~mL}$ of distilled water was added, previously measured in a $1000 \mathrm{~mL}$ volumetric flask, and the displaced liquid was collected using a $250 \mathrm{~mL}$ graduated cylinder.

To obtain the reference surface area, the pericarp was manually extracted from the fruit in vertical strips using a stainless-steel knife (Guillete ${ }^{\circledR}$ ). The strips were digitalized with a scanner, model HP Scanjet 3770, and the surface area of each one was measured using the calibration technique (Figure 6).

\section{Data analysis}

The technique's precision was determined in terms of the mean coefficient of variation, and its accuracy as the mean relative error (Equation 4). In addition, a simple regression analysis (Equation 5) was carried out. The data were processed with R-Project ${ }^{\circledR}$ within the R-Studio ${ }^{\circledR}$ interface.

$$
\operatorname{Err}(\%)=\left|\frac{x_{0}-x_{1}}{x_{0}}\right| * 100
$$

where $x_{0}$ is the value measured using the reference method $\left(\mathrm{cm}^{2}\right.$ or $\left.\mathrm{cm}^{3}\right)$; and $x_{1}$ is the value estimated using the digital images $\left(\mathrm{cm}^{2}\right.$ or $\left.\mathrm{cm}^{3}\right)$.
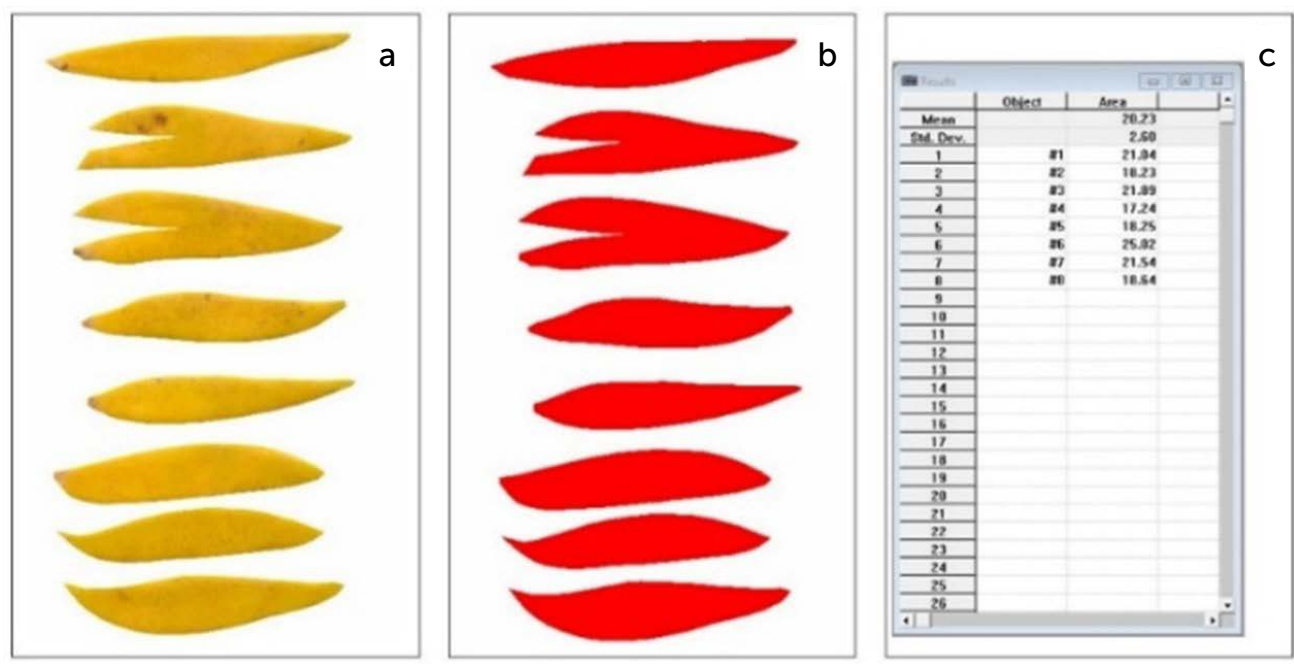

Figure 6. a) Mango fruit's pericarp, b) segmented image y, c) individual surface 


$$
y=\beta_{0}+\beta_{1} * x+e
$$

where $y$ is the reference surface area or volume $\left(\mathrm{cm}^{2}\right.$ or $\left.\mathrm{cm}^{3}\right) ; x$ is the surface area or volume of the fruit, estimated using the digital images; $\beta_{0}$ is the ordinate of the origin; $\beta_{1}$ is the slope; and $e$ is the random error NIID $\left(0, \sigma^{2}\right)$.

\section{RESULTS AND DISCUSSION}

\section{Estimation of total surface area of the fruit}

The surface area estimated using the digital images segmented using the red channel $(R C)$ presented a lower standard deviation and coefficient of variation $\left(3.07 \mathrm{~cm}^{2}\right.$ and $\left.1.39 \%\right)$, while the greatest variation was found in the images segmented using color intensity (I) (Table 1). Sabliov et al. (2002) found lower values $\left(0.32 \mathrm{~cm}^{2}\right)$ applying this method on spheres and lime fruit, but found higher values on lemon $\left(3.7 \mathrm{~cm}^{2}\right)$ and peach $\left(3.6 \mathrm{~cm}^{2}\right)$. This could possibly be due to the difficulty in placing the fruit in the same position.

In all cases, the fruit surface area was overestimated (Figure 7). However, the greatest accuracy was obtained from the images segmented using the red channel $(R C)$, with a relative error of $2.19 \%$, while the images segmented using color intensity $(I)$ had $2.36 \%$ error; this rise in error could be caused by the blue channel, since it did not provide information individually for segmentation. Sabliov et al. (2002) attributed overestimation to the threshold method, and in this case, it can be attributed to the pericarp contracting after being removed from the fruit.

The estimation error was found in what was reported for other products such as eggs with $0.82 \%$ using a 3D scanner (Uyar and Erdogdu, 2009), limes with 2.95\%, and peaches with $6.0 \%$ using image processing (Sabliov et al., 2002).

The determining coefficient was 0.97 in all cases (Table 1) and is close to the values reported for strawberry
(0.96) using 30 digital images (Eifer et al., 2006), for banana (0.97) using a model that obtains geometric parameters from digital images, and orange (0.92) using two orthogonal images (Khojastehnazhand et al., 2009).

\section{Estimation of fruit volume}

The greatest accuracy in volume estimation was obtained from the images segmented using the red channel $(R C)$ with a standard deviation of $4.88 \mathrm{~cm}^{3}$ and a variation coefficient of $1.70 \%$. These results are greater than those reported in spheres $\left(0.07 \mathrm{~cm}^{3}\right)$, egg $\left(4.0 \mathrm{~cm}^{3}\right)$, and lime $\left(3.4 \mathrm{~cm}^{3}\right)$, but less than those reported in lemon $\left(6.6 \mathrm{~cm}^{3}\right)$ and peach $\left(4.8 \mathrm{~cm}^{3}\right)$ by Sabliov et al. (2002).

The volume obtained by this technique was underestimated by less than 5.0\% (Table 2 and Figure 8). The error in volume estimation for diverse products was: $2.0 \%$ in apple (Goñi et al., 2007), 2.6\% in mandaris (Khojastehnazhand et al., 2010), 3.5\% in egg (Uyar and Erdogdu, 2009), 3.7\% in onion (Wang and Li, 2014), 4.56\% in cucumber, and up to $7.8 \%$ in watermelon (Koc, 2007).

The coefficient of determination $\left(R^{2}\right)$ found in this study was 0.93 for the red channel $(R C)$ and 0.94 for the other two discriminants. These values are similar to those

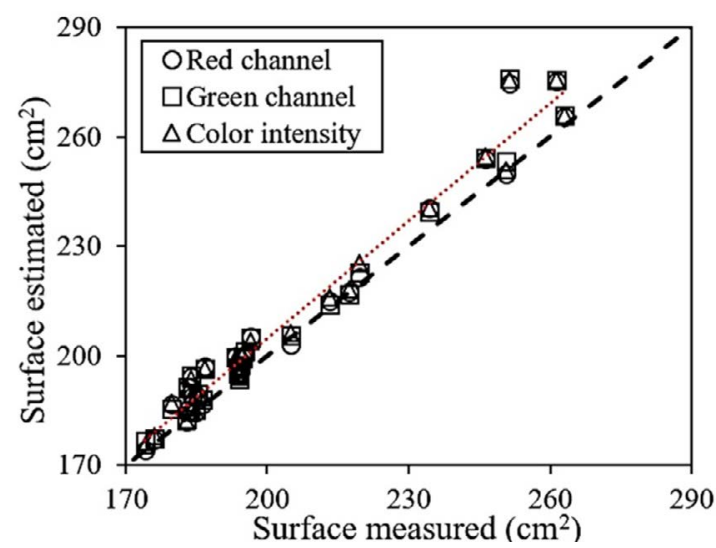

Figure 7. Surface of 'Ataulfo' mango fruit estimated by digital image analysis using different discriminants for segmentation.

\begin{tabular}{|c|c|c|c|c|c|c|}
\hline Discriminant & $s d\left(\mathrm{~cm}^{2}\right)$ & C.V. $(\%)$ & $\operatorname{Err}(|\%|)$ & $\beta_{0}(\mathrm{P})$ & $\beta_{1}(\mathrm{P})$ & $R^{2}$ \\
\hline$R C$ & 3.07 & 1.39 & 2.19 & $14.57(0.029)$ & $0.91(<0.001)$ & 0.97 \\
\hline$G C$ & 3.34 & 1.50 & 2.32 & $14.95(0.019)$ & $0.91(<0.001)$ & 0.97 \\
\hline 1 & 3.39 & 1.53 & 2.36 & $14.59(0.019)$ & $0.91(<0.001)$ & 0.97 \\
\hline
\end{tabular}

Discriminant: RC: Red channel; GC: Green channel; I: HSI color intensity. 
Table 2. Volume of mango fruit estimated by digital image analysis. Standard deviation (sd), coefficient of variation (C.V.), relative error $(E r r)$, intercept $\left(\beta_{0}\right)$, slope $\left(\beta_{1}\right)$ and coefficient of determination $\left(R^{2}\right)$.

\begin{tabular}{c|c|c|c|c|c|c|c}
\hline Discriminant & sd $\left(\mathrm{cm}^{3}\right)$ & C.V. $(\%)$ & $\operatorname{Err}(|\%|)$ & $\beta_{0}(\mathrm{P})$ & $\beta_{1}(\mathrm{P})$ & $R^{2}$ \\
\hline$R C$ & 4.88 & 1.70 & 4.73 & $30.34(0.013)$ & $0.92(<0.001)$ & 0.93 \\
\hline$G C$ & 5.03 & 1.74 & 4.71 & $28.56(0.019)$ & $0.92(<0.001)$ & 0.94 \\
\hline 1 & 4.95 & 1.73 & 4.72 & $29.46(0.015)$ & $0.92(<0.001)$ & 0.94 \\
\hline
\end{tabular}

Discriminant: RC: Red channel; GC: Green channel; I: HSI color intensity.

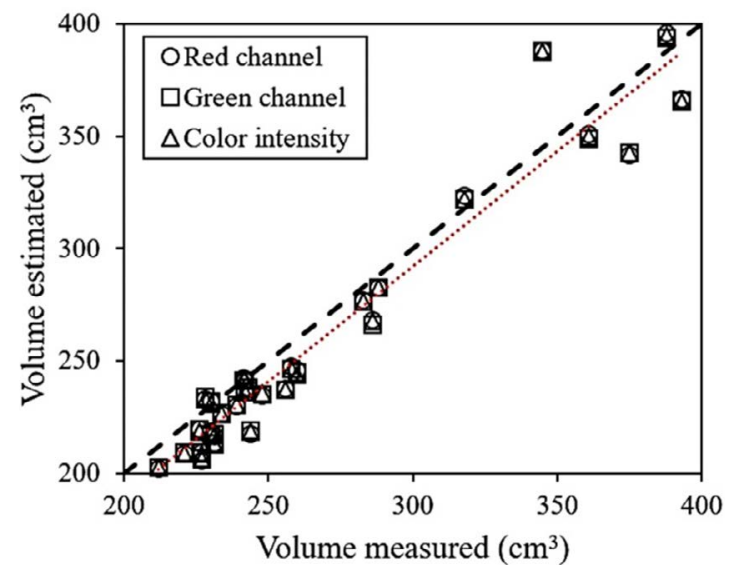

Figure 8. Volume of of 'Ataulfo' mango fruit estimated by digital image analysis using different discriminants for segmentation.

reported for mandarin (0.96) (Khojastehnazhand et al., 2010), orange (0.99) (Khojastehnazhand et al., 2009), onion (0.96 to 0.98) (Wang and Li, 2014), and apple (0.99) (Goñi et al., 2007).

\section{CONCLUSION}

The proposed technique in this study is a non-destructive alternative to estimate the surface area and volume of "Ataulfo" mango fruit with a reasonable error margin and can be implemented directly on an Android $^{\circledR}$ device using the red channel as the only discriminant for segmentation.

\section{REFERENCES}

Baldor J. A., M. Santoló S. y P. E. Suardiaz C. (1997). Geometría Plana y del Espacio y Trigonometría. Publicaciones Cultural S.A. de C.V. México. 670 p.

Cubero, S., Albert F., Prats-Moltalbán J. M., Fernández-Pacheco D. G., Blasco J. and Aleixos N. (2018). Application for the estimation of the standard citrus colour index (CCl) using image processing in mobile devices. Biosysts. Engineering. 167:63-74.

Eifert, J. D., G. C. Sanglay, D. J. Lee, S. S. Sumner and M. D. Pierson. (2006). Prediction of raw produce surface area from weight measurement. J. Food Eng. 74(4):552-556.

Fellegari, R. and H. Navid. (2011). Determining the orange volume using image processing. Int. Conf. on Food Engineering and Biotechnology 9(2011):180-184.

Gonzalez, R. C. and E. Woods. (2007). Digital Image Processing. 3er Ed Prentice Hall. USA. $954 \mathrm{p}$.
Goñi, S. M., E. Purlis and V. O. Salvadori. (2007). Three-dimensional reconstruction of irregular foodstuffs. J. Food Eng. 82(4):536-547.

Kelkar, S., S. Scott, C. Boushey and M. Okos. (2011). Developing novel 3D measurement techniques and prediction method for food density determination. Procedia Food Sci. 1:483-491.

Khojastehnazhand, M., M. Omid and A. Tabatabaeefar. (2009). Determination of orange volume and surface area using image processing technique. Int. Agrophys. 23:237-242.

Khojastehnazhand, M., M. Omid and A. Tabatabaeefar. (2010). Determination of tangerine volume using image processing methods. Int. J. Food Prop. 13(4):760-770

Koc, A-B. (2007). Determination of watermelon volume using ellipsoid approximation and image processing. Postharvest Biol. Technol. 45(3):366-371.

Palafox-Carlos, H., E. M. Yahia and G. A. González-Aguilar. (2012). Identification and quantification of major phenolic compounds from mango (Mangifera indica, cv. Ataulfo) fruit by HPLC-DADMS/MS-ESI and their individual contribution to the antioxidant activity during ripening. Food Chemistry 135 (2012): 105-111.

Sabliov, C. M., D. Boldor, K. M. Keener and B. Farkas. (2002). Image processing method to determine surface area and volume of axisymmetric agricultural products. Int. J. Food Prop. 5(3): 641-653.

Saltani, M., R. Alimardani and M. Omid. (2011). Modeling the main physical properties of banana fruit based on geometrical attributes. International Journal of Multidisciplinary Sciences and Engineering 2(2): 1-6.

Sáyago-Ayerdi, S. G., C. L. Moreno-Hernández, E. Montalvo-González, M. L. García-Magaña, M. Mata-Montes de Oca, J. L. Torres and J. Pérez-Jiménez. (2013). Mexican 'Ataulfo' mango (Mangifera indica L) as a source of hydrolyzable tannins. Analysis by MALDITOF/TOF MS. Food Research International 51 (2013): 188-194.

Spreer, W. and J. Müller. (2011). Estimating the mass of mango fruit (Mangifera indica, cv. Chok Anan) from its geometric dimensions by optical measurement. Comput. Electron. Agric 75(1): 125-131.

Teoh, C., and A. R. M. Syaifudin. (2007). Image processing and analysis techniques for estimating weight of Chokanan mangoes. J Trop Agric Food Sci 35(1):183-190.

Uyar, R. and F. Erdogdu. (2009). Potential use of 3-dimensional scanners for food process modeling. J. Food Eng. 93(3): 337-343.

Valle-Guadarrama, S., A. Gómez-Cruz, F. Cruz-Cruz y A. Chan-Chi. (2009). Modelado de una atmósfera modificada para conservar frutos de tomate de cáscara (Physalis ixocarpa). Ingeniería Agrícola y Biosistemas. 1(1): 33-38.

Vesali, F., M. Omid, H. Mobli and A. Kaleita. (2017). Feasibility of using smart phones to estimate chlorophyll content in corn plants. Photosynthetica. 55(4): 603-610.

Wang, W. and C. Li. (2014). Size estimation of sweet onions using consumergrade RGB-depth sensor. J. Food Eng. 142(2014): 153-162. 